\title{
Metabolic and Hemodynamic Effects of Saline Infusion to Maintain Volemia on Temporary Abdominal Aortic Occlusion
}

\author{
Fábio Ferreira Amorim, Bruno do Vale Pinheiro, Hélio Romaldini \\ São Paulo, SP - Brazil
}

\begin{abstract}
Objective - To analyze hemodynamic and metabolic effects of saline solution infusion in the maintenance of blood volume in ischemia-reperfusion syndrome during temporary abdominal aortic occlusion in dogs.
\end{abstract}

Methods - We studied 20 dogs divided into 2 groups: the ischemia-reperfusion group (IRG, $n=10$ ) and the ischemia-reperfusion group with saline solution infusion aiming at maintaining mean pulmonary arterial wedge pressure between 10 and $20 \mathrm{mmHg}(I R G-S S, n=10)$. All animals were anesthetized with sodium thiopental and maintained on spontaneous ventilation. Occlusion of the supraceliac aorta was obtained with inflation of a Fogarty catheter inserted through the femoral artery. After 60 minutes of ischemia, the balloon was deflated, and the animals were observed for another 60 minutes of reperfusion.

Results - IRG-SS dogs did not have hemodynamic instability after aortic unclamping, and the mean systemic blood pressure and heart rate were maintained. However, acidosis worsened, which was documented by a greater reduction of arterial $p H$ that occurred especially due to the absence of a respiratory response to metabolic acidosis that was greater with the adoption of this procedure.

Conclusion - Saline solution infusion to maintain blood volume avoided hemodynamic instability after aortic unclamping. This procedure, however, caused worsening in metabolic acidosis in this experimental model.

Keywords: reperfusion lesion, hemodynamic, volemia

Universidade Federal de São Paulo (Federal University of São Paulo) - Escola Paulista de Medicina (Paulista School of Medicine)

Mailing address: Fábio Ferreira Amorim - Shis, QI. 15 - Conj. 03 - Casa 10 - 71635-230 Brasília, DF - E-mail: ffamorim@ig.com.br
Temporary aortic occlusion, necessary in surgical procedures, is a condition that can lead to ischemia-reperfusion lesions with systemic alterations ${ }^{1,2}$. Severe hypotension, associated with a decrease in cardiac output is a well-known event occurring after declamping, and hypovolemia is considered the main cause of this event ${ }^{3-8}$. Maintenance of renal function, prevention of hepatic and splanic circulatory failure and preservation of gastroinstestinal tract intensity are important consequences of hemodynamic stability ${ }^{8-11}$.

Fluid administration followed by adequate monitoring based on the physiology of cardiac function, according to the Frank-Starling mechanism, promotes good myocardial performance during surgical stress and in the postoperative period. It improves cardiac output and maintains systemic blood pressure, which is important for maintaining adequate coronary blood flow, thereby protecting the heart, especially in patients with significant coronary occlusive disease ${ }^{11}$. Several authors ${ }^{4-6,12,13}$ showed that maintenance of pulmonary artery wedge pressure between 10 and $18 \mathrm{mmHg}$ during this procedure could prevent a decline in cardiac output and hypotension after aortic declamping.

However, management of fluid infusion is difficult in these patients due to the complexity of factors involved, such as preoperative cardiac function and multiple risk factors present in the intraoperative period, such as administering anesthetic drugs and mechanical positive pressure ventilation. This is important especially in these patients that usually have heart disease, where inappropriate volume loading is dangerous ${ }^{5}$.

Acknowledging the importance of the study of ischemia-reperfusion lesion and knowing the capacity of it in determining systemic alterations, even in distant organs, we studied the effects of saline solution infusion to maintain mean pulmonary artery wedge pressure between 10 and $20 \mathrm{mmHg}$ during aortic ischemia-reperfusion in an experimental model in dogs, especially in the shock phase after aortic declamping, over hemodynamic and metabolic alterations.

\section{Methods}

Twenty adult, male, mongrel dogs, weighing between 12 and $23 \mathrm{~kg}$ were intravenously anesthetized with sodium 
Thionembutal (sodium thiopental ${ }^{\circledR}$ CEME, Ministério da Saúde, Brasil) (Brazil's Health Department) at $20 \mathrm{mg} / \mathrm{kg}$ dosage of body weight, receiving additional dosages of $5 \mathrm{mg} / \mathrm{kg}$ during the procedure, according to the need to maintain the anesthetic plan. After anesthesia, dogs underwent endotracheal intubation with a Rusch cannula number 8 and were ventilated spontaneously throughout the experiment.

An 8F-polyethylene catheter was introduced through the right femoral artery, and its distal end was located in the distal abdominal aorta for monitoring mean abdominal aortic artery pressure distal to the occlusion. Later, the left femoral artery was dissected and catheterized with an 8F Fogarty occlusor, and the balloon was positioned in the descending thoracic aorta adjacent to the diaphragm at the level of the 10th thoracic vertebra for posterior occlusion. Aortic occlusion was therefore performed above the celiac trunk. Physical examination, laparotomy, and thoracotomy confirmed in all dogs the correct position of the balloon at the end of the procedure.

The right internal jugular vein was dissected with a right cervicotomy, and a 7F thermodilution pulmonary artery catheter triple lumen model with its progression control performed through the interpretation of pressure curves SDM2000 monitor (Dixtal Tecnologia, Brazil) with its distal tip placed in the pulmonary artery. The proximal and distal portions of the pulmonary artery catheter were connected to a pressure transducer (Statham P23 Db), enabling the determination of pressure curves of the right atrium, pulmonary artery, and pulmonary arterial wedge. This pressure is estimated through the pulmonary artery occlusion pressure, obtained with balloon inflation of the distal end of the catheter. Cardiac output was determined by the thermodilution technique ${ }^{13}$ with the debitometer of a SDM2000 monitor (Dixtal Tecnologia, Brazil). Through the same incision, the right carotid artery was dissected, and an 8F-polyethylene catheter was used to assess mean systemic arterial pressure above the level of aortic occlusion.

Dogs were randomly distributed into 2 groups: the ischemia-reperfusion group $(\mathrm{n}=10)$ and the ischemia-reperfusion with saline infusion $(\mathrm{n}=10)$. In both groups, we established as criteria for the beginning of the experiment: $\mathrm{pH}$ in arterial blood $(\mathrm{pHa}) \geq 7.25$, partial oxygen pressure in arterial blood $\geq 70 \mathrm{mmHg}$, mean pulmonary arterial wedge pressure $\geq 5 \mathrm{mmHg}$, and mean systemic arterial pressure $\geq 90 \mathrm{mmHg}$.

In the ischemia-reperfusion group (IRG), after we obtained hemodynamic parameters and basal blood samples (T0), Fogarty catheter inflation was performed until mean systemic arterial pressure below the occlusion reached values between 10 and $20 \mathrm{mmHg}$ and mercury column oscillation was not observed. The catheter was maintained inflated for 60 minutes. After this period, reperfusion through balloon deflation started. The animal was observed for another 60 minutes of reperfusion, and then they were put to death by venous administration of $50 \mathrm{mEq}$ of potassium chloride. Hemodynamic assessments were repeated at the following times: 10 minutes of ischemia (T10-I), 45 minutes of ischemia (T45-I), 5 minutes of reperfusion(T5-R), 30 minutes of reperfusion (T30-R), and 60 minutes of reperfusion (T60-R). In the ischemia-reperfusion group with volemic repositioning with saline solution (IRG-SS), dogs underwent the same procedures and the same monitoring. The difference from the IRG group was the administration of saline solution aiming at maintaining mean pulmonary arterial wedge pressure between 10 and $20 \mathrm{mmHg}$ throughout the experiment. To that end mean, the infusion of $209 \mathrm{~mL} / \mathrm{kg}$ of saline solution per dog in the IRG-SS group was necessary during the procedure.

Hemodynamic parameters studied were: mean systemic arterial pressure, mean pulmonary arterial wedge pressure, heart rate, mean pulmonary artery pressure, mean right atrial pressure, cardiac index, systolic index, systemic vascular resistance index, and pulmonary vascular resistance index. Metabolic parameters studied were: arterial $\mathrm{pH}$, arterial bicarbonate $\left(\mathrm{HCO}_{3}\right)$, and lactate. In addition to these parameters, partial carbonic gas in arterial blood was also as$\operatorname{sessed}\left(\mathrm{PCO}_{2}\right)$.

Differences among the groups, regarding hemodynamic and metabolic variables were studied through multivariate analysis of profiles with repeated measures, analyzing variations in relation to baseline values and parallelism and the coincidence of parameters between both groups ${ }^{15}$. Accepted significance level was $5 \%(\mathrm{p}<0.05)$.

The experiments were performed with the approval of the ethics committee of the Escola Paulista de Medicina (Paulista Medical School), Universidade Federal de São Paulo (Federal University of São Paulo).

\section{Results}

Significant hemodynamic parameters are shown in tables I and II. Aortic occlusion caused similar results in the 2 groups with an increase in mean systemic arterial pressure and a decrease in cardiac index. However, after aortic declamping, the IRG group had hypotension, which did not occur in the IRG-SS group $(\mathrm{p}=0.004$ for parallelism between the groups). The same pattern was observed regarding cardiac index after aortic declamping. Deterioration occurred in the IRG group, and a return to baseline values occurred in the IRG-SS group ( $\mathrm{p}=0.01$ for parallelism between the groups). No difference existed between both groups regarding heart rate $(\mathrm{p}=0.59$ for parallelism and $\mathrm{p}=0.73$ for coincidence between the groups). In the IRG-SS group, mean pulmonary arterial wedge pressure during all the procedure had values in accordance with those that were previously stipulated for this experimental model, that is, maintaining it between 10 and $20 \mathrm{mmHg}$. Additionally, a decrease occurred in the mean pulmonary arterial wedge in the IRG group at the times $\mathrm{T} 45-\mathrm{R}$ and $\mathrm{T} 60-\mathrm{R}$ ( $\mathrm{p}=0.000$ for parallelism between the groups). Analyzing mean right atrial pressure, an increase in this parameter in both groups was observed after aortic occlusion. However, during the reperfusion period, a decrease occurred in it in the IRG group regarding baseline values, which did not occur in the IRG-SS group ( $p=0.03$ for parallelism between the groups). Additionally, in 


\begin{tabular}{|c|c|c|c|c|c|c|c|c|}
\hline & \multicolumn{2}{|c|}{ SAP } & \multicolumn{2}{|c|}{ CI } & \multicolumn{2}{|c|}{ SI } & \multicolumn{2}{|c|}{ HR } \\
\hline & IRG & IRG-SS & IRG & GIRG-SS & IRG & IRG-SS & IRG & IRG-SS \\
\hline T0 & $133 \pm 12$ & $128 \pm 17$ & $5.70 \pm 1.17$ & $5.79 \pm 2.72$ & $38.5 \pm 4.1$ & $37.1 \pm 16.0$ & $149 \pm 30$ & $158 \pm 23$ \\
\hline T10-I & $174 \pm 24^{b}$ & $176 \pm 24^{b}$ & $4.96 \pm 1.83$ & $5.73 \pm 1.69$ & $35.8 \pm 8.3$ & $34.7 \pm 11.0$ & $139 \pm 40$ & $158 \pm 31$ \\
\hline T45-I & $175 \pm 20^{b}$ & $161 \pm 28^{b}$ & $4.26 \pm 1.31^{a}$ & $4.07 \pm 1.12^{a}$ & $29.2 \pm 8.7^{a}$ & $28.8 \pm 9.4^{a}$ & $151 \pm 32$ & $145 \pm 22$ \\
\hline T5-R & $97 \pm 27^{b}$ & $120 \pm 23$ & $2.72 \pm 0.69^{b}$ & $5.25 \pm 0.92$ & $21.0 \pm 3.9^{b}$ & $36.6 \pm 7.0$ & $133 \pm 38$ & $146 \pm 26$ \\
\hline T45-R & $101 \pm 14^{b}$ & $124 \pm 20$ & $2.65 \pm 0.81^{b}$ & $5.47 \pm 1.54$ & $18.0 \pm 4.8^{b}$ & $40.3 \pm 13.2$ & $147 \pm 24$ & $141 \pm 28$ \\
\hline T-60-R & $94 \pm 14^{b}$ & $117 \pm 18$ & $2.47 \pm 0.63^{b}$ & $5.28 \pm 1.42$ & $16.7 \pm 4.2^{b}$ & $38.8 \pm 13.1$ & $149 \pm 30$ & $142 \pm 29$ \\
\hline
\end{tabular}

Values are expressed as mean \pm standard deviation; SAP- mean systemic arterial pressure; CI- cardiac index; SI- systolic index; HR- heart rate; $a$ - $\mathrm{P}<0.05$ in relation to baseline values; $b-\mathrm{p}<0.01$ in relation to baseline value, $\mathrm{Tx}-\mathrm{I} / \mathrm{Tx}-\mathrm{R}$ ( $\mathrm{T}=\mathrm{Time}, \mathrm{x}=$ minutes, $\mathrm{I}=\mathrm{ischemia}, \mathrm{R}=$ reperfusion).

\begin{tabular}{|c|c|c|c|c|c|c|c|c|}
\hline & \multicolumn{2}{|c|}{ PAWP } & \multicolumn{2}{|c|}{ RAP } & \multicolumn{2}{|c|}{ PVRI } & \multicolumn{2}{|c|}{ SVRI } \\
\hline & IRG & IRG-SS & IRG & IRG-SS & IRG & IRG-SS & IRG & IRG-SS \\
\hline T0 & $7 \pm 2$ & $7 \pm 3$ & $1 \pm 2$ & $3 \pm 2$ & $159 \pm 38$ & $200 \pm 122$ & $1929 \pm 448$ & $2164 \pm 1121$ \\
\hline T10-I & $13 \pm 8$ & $19 \pm 5^{b}$ & $4 \pm 2^{b}$ & $9 \pm 3^{b}$ & $159 \pm 55$ & $181 \pm 115$ & $3121 \pm 1202$ & $2781 \pm 1058$ \\
\hline T45-I & $11 \pm 4$ & $18 \pm 5^{b}$ & $4 \pm 2^{b}$ & $7 \pm 2^{b}$ & $180 \pm 48$ & $216 \pm 99$ & $3518 \pm 1221$ & $3305 \pm 1065$ \\
\hline T5-R & $3 \pm 2$ & $13 \pm 5^{b}$ & $-1 \pm 2^{a}$ & $5 \pm 3$ & $285 \pm 73^{b}$ & $183 \pm 81$ & $2893 \pm 544^{b}$ & $1809 \pm 492$ \\
\hline $\mathrm{T} 45-\mathrm{R}$ & $2 \pm 1^{b}$ & $12 \pm 2^{b}$ & $-2 \pm 2^{b}$ & $4 \pm 2$ & $350 \pm 98^{b}$ & $171 \pm 83$ & $3431 \pm 1176^{b}$ & $1899 \pm 670$ \\
\hline T-60-R & $2 \pm 1^{b}$ & $10 \pm 2^{b}$ & $-1 \pm 1^{a}$ & $3 \pm 2$ & $389 \pm 123^{b}$ & $190 \pm 122$ & $3300 \pm 894^{b}$ & $1942 \pm 977$ \\
\hline
\end{tabular}

the IRG-SS group, systemic vascular resistance index $(\mathrm{p}=0.04$ for parallelism between the groups) and pulmonary vascular resistance index ( $\mathrm{p}=0.002$ for parallelism between the groups) had smaller values after release of the aortic clamp, when compared with that in the IRG group.

Significant metabolic parameters are shown in table III. Metabolic acidosis was greater in the IRG-SS group $(p=0.046$ for coincidence between the groups) with arterial bicarbonate always having lower values in the IRG-SS group compared with that in the IRG group ( $\mathrm{p}=0.003$ for parallelism between the groups). Additionally, respiratory acidosis associated with metabolic acidosis was present in the IRG-SS group, as observed by the evolvement of $\mathrm{PaCO}_{2}(\mathrm{p}=0.007$ for coincidence between the groups), mixed acidosis therefore occurring.

Regarding lactate, no significant statistical difference existed between the 2 groups ( $\mathrm{p}=0.80$ for parallelism and $\mathrm{p}=0.88$ for coincidence). An increase in lactate regarding baseline values was observed throughout the experiment.

\section{Discussion}

Our study showed that saline infusion with maintenance of mean pulmonary arterial wedge pressure is suitable for minimizing hemodynamic changes after release of the aortic clamps, mainly avoiding hypotension and decrease in the cardiac index. Previous studies demonstrated that correction of central hypovolemia with consequent mainte- nance of preload before and during release of the aortic clamps may avoid hypotension after aortic declamping ${ }^{3-6,8}$. In an experimental study in dogs, Perry ${ }^{3}$ avoided hypotension through infusion of Ringer's lactate solution (at $5 \%$ of body weight) before aortic declamping. Falk et al ${ }^{4}$, studying the effect of infrarenal aortic cross-clamping in cardiac function, showed that severe hypotension after aortic declamping did not occur when mean pulmonary arterial wedge pressure was maintained from 10 to $15 \mathrm{mmHg}$. Several groups avoided hypotension by maintaining it at $4 \mathrm{mmHg}$ above baseline levels during aortic occlusion and also measuring pulmonary arterial wedge pressure. Additionally, it was observed that when pulmonary arterial wedge pressure was maintained above $10 \mathrm{mmHg}$, a decrease in systemic arterial pressure was avoided ${ }^{5,6}$.

Cardiac index after aortic declamping is not the same in the several studies. It may increase ${ }^{16}$, decrease ${ }^{3}$, or remain unchanged ${ }^{1,17}$. These results may be due to the role of several mechanisms that occur after aortic declamping, because although releasing the aortic clamps decreases systemic vascular resistance, facilitating blood ejection through the left ventricle, reperfusion may release several mediators with depressing activity over myocardial function ${ }^{18-21}$. Furthermore, preload interferes with the final cardiac index and systolic index, which are stable or increased when preload is appropriate ${ }^{17}$. The importance of volume loading in cases of aortic ischemia-reperfusion was well dis- 


\begin{tabular}{|c|c|c|c|c|c|c|c|c|}
\hline & \multicolumn{2}{|c|}{$\mathrm{pHa}$} & \multicolumn{2}{|c|}{$\mathrm{HCO}_{3}$} & \multicolumn{2}{|c|}{$\mathrm{PaCO}_{2}$} & \multicolumn{2}{|c|}{ Lactato } \\
\hline & IRG & IRG-SS & IRG & IRG-SS & IRG & IRG-SS & IRG & IRG-SS \\
\hline T0 & $7.28 \pm 0.08$ & $7.31 \pm 0.07$ & $18.5 \pm 2.9$ & $19.1 \pm 3.4$ & $41 \pm 8$ & $40 \pm 6$ & $13 \pm 4$ & $12 \pm \quad 6$ \\
\hline T10-I & $7.22 \pm 0.11$ & $7.13 \pm 0.07^{b}$ & $16.9 \pm 2.7^{a}$ & $14.5 \pm 2.0^{b}$ & $44 \pm 5$ & $46 \pm 4^{a}$ & - & - \\
\hline T45-I & $7.20 \pm 0.10^{a}$ & $7.08 \pm 0.08^{b}$ & $12.8 \pm 2.5^{b}$ & $12.1 \pm 1.7^{b}$ & $34 \pm 6^{a}$ & $42 \pm 4$ & $35 \pm 10^{b}$ & $36 \pm 18^{b}$ \\
\hline T5-R & $7.11 \pm 0.11^{b}$ & $7.01 \pm 0.10^{b}$ & $10.6 \pm 2.8^{b}$ & $10.3 \pm 1.6^{b}$ & $34 \pm 6^{a}$ & $43 \pm 7$ & $46 \pm 16^{b}$ & $48 \pm 21^{b}$ \\
\hline T45-R & $7.15 \pm 0.13^{a}$ & $7.03 \pm 0.14^{b}$ & $11.4 \pm 2.7^{b}$ & $10.5 \pm 1.7^{b}$ & $33 \pm 6$ & $44 \pm 13$ & - & - \\
\hline T-60-R & $7.17 \pm 0.14$ & $7.03 \pm 0.16^{b}$ & $11.8 \pm 3.0^{b}$ & $10.7 \pm 2.0^{b}$ & $33 \pm 7$ & $44 \pm 13$ & $28 \pm 15^{b}$ & $22 \pm 13^{a}$ \\
\hline
\end{tabular}

cussed in our study in which decreases in cardiac index and systolic index were avoided through this procedure. A study presenting the importance of the volemic state in procedures with aortic occlusion and release of the clamps occluding the aorta was performed by Huval et al ${ }^{12}$, who showed prevention of myocardial function depression in patients undergoing aortic aneurism resection if adequate volume load is maintained to keep pulmonary arterial wedge pressure above $10 \mathrm{mmHg}$. They also observed that ibuprofen (cyclo-oxygenase inhibitor that eliminates thromboxane $\mathrm{A}_{2}$ synthesis) was effective in maintaining cardiac index only in patients that kept these levels of pulmonary arterial wedge pressure.

In spite of hemodynamic improvement, acidosis worsened with volume loading. A decrease in $\mathrm{pHa}$ in both groups, was observed right after aortic declamping, probably due to the lactate washout phenomenon and its consequent increase in arterial blood ${ }^{22}$. Greater acidosis, present in the group where volume loading was performed, was probably due to metabolic acidosis present in this group in association with lactic and renal acidosis, and the presence of respiratory acidosis, which can be seen by the evolvement of $\mathrm{PaCO}_{2}$. Studies previously performed in experimental models with dogs and human beings showed an increase in renin activity, causing elevation in angiotensin II concen- tration during procedures of aortic cross-clamping and unclamping, which can be easily explained by the decrease in perfusion in afferents arterioles during ischemia ${ }^{23-25}$. The major effects of angiotensin II are increase in vascular renal resistance and tubular sodium absorption, acting directly on the tube and indirectly through the increase in aldosterone production ${ }^{26}$. This increased sodium tubular reabsorption is followed by chloride absorption either hydrogen or potassium ion secretion, to maintain neutrality of tubular renal electric potential. Thus, an increase in the amount of chloride, which occurs in association with administration of large volumes of saline, determines a decrease in hydrogen and potassium ion secretion resulting in a hyperchloremic metabolic acidosis with normal anion gap ${ }^{11}$.

Therefore, we may conclude that saline infusion to maintain blood volume, in this experimental model, avoided hemodynamic instability after aortic declamping. However, this procedure resulted in worsening of acidosis with the presence of mixed acidosis, which may be observed by arterial bicarbonate and $\mathrm{PaCO}_{2}$ in both groups. These results raise the perspective of new studies about the effects of saline infusion in this type of ischemia-reperfusion model, especially those related to reperfusion pulmonary lesion, pulmonary gas exchange, and use of oxygen by the tissues.

\section{References}

1. Dunn E, Prager RL, Frey W, Firsh MM. The effect of abdominal aortic crossclamping on myocardial function. J Surg Res 1977; 22: 463-7.

2. Provan JL, Fraenkel GJ, Austen WG. Metabolic and hemodynamic changes after temporary aortic occlusions in dogs. Surg Gynec Obstet 1966; 123: 544-50.

3. Perry MO. The hemodynamic of temporary abdominal aortic occlusion. Ann Surg 1968; 168: 193-200.

4. Falk JL, Rackow EC, Blumberg R, Gelfand M, Fein IA. Hemodynamic and metabolic effects of abdominal aortic crossclamping. Am J Surg 1981; 142: 174-8.

5. Bush LL, Lo Gerfo FW, Weisel RD, Mannick JA, Hechtman HB. Assesment of myocardial performance and optimal volume loading during elective abdominal aortic aneurysm ressection. Arch Surg 1977; 112: 1301-5.

6. Lunn JK, Dannemiller FJ, Stanley TH. Cardiovascular responses to clamping of the aorta during epidural and general anesthesia. Anesth Analg 1979; 58: 372-6.

7. Grindlinger GA, Vegas AM, Manny J, Bush HL, Mannick JA, Hechtman, HB.
Volume loading and vasodilators in abdominal aortic aneurysmectomy. Am J Surg 1980; 139: 480-6.

8. Whittemore AD, Clowes AW, Hechtman HB, Mannick JA. Aortic aneurysm repair: reduced operative mortality associated with maintenance of optimal cardiac performance. Ann Surg 1980; 192: 414-21.

9. Silverstein PR, Caldera DL, Cullen DJ, Davison JK, Darling RC, Emerson CW. Avoiding the hemodynamic consequence of aortic cross-clamping and unclamping. Anesthesiology 1979; 50: 462-6.

10. Skillman JJ, Patel RC, Klick JM. Cardiac performance testing by volume loading and lower-extremity compression. Arch Surg 1982; 117: 1009-11.

11. Rosenthal MH. Intraoperative fluid management - what and how much? Chest 1999; 115: 106S-112S

12. Huval WV, Lelcuk S, Allen PD, Mannick JA, Shiepro D, Heichtman HB. Determinants of cardiovascular stability during abdominal aortic aneurysmectomy (AAA). Ann Surg 1984; 199: 216-22. 
13. Reiz S, Peter, T, Rais, Hemodynamic and cardiometabolic effects of infrarenal and commom iliac artery declamping in man - an approach to optimal volume loading. Acta Anaesth Scand 1979: 579-86.

14. KhalilHH, Richardson TA, Guyton AC. Measurement of cardiac output by thermaldilution and direct Fick methods in dogs. J Apply Physiol 1966; 21: 1131-5.

15. Singer JM, Andrade DF. Análise de Dados Longitudinais. Campinas; 1986, 106p.

16. Roberts AJ, Nora JD, Hughes WA, Quintanilla AP, et al. Cardiac and renal responses to cross-clamping of the descending thoracic aorta. J Thorac Cardiovasc Surg 1983; 86: 732-41

17. Vandermeer, TJ, Maini BS, Hendershott TH, Sottile FD. Evaluation of right ventricular function during aortic operations. Arch Surg 1993; 128: 582-5.

18. Williams Jr LF, Goldberg AH, Polansky BJ, Byrne JJ. Myocardial effects of intestinal ischemia. J Surg Res 1969; 9: 319-23.

19. Lefer AM, Martin J. Origin of myocardial depressant factor in shock. Am J Physiol 1970; 218: 1423-7.

20. Mathieson MA, Dunham BM, Huval WV, et al. Ischemia of the limb stimulates thromboxane production and myocardial depression. Surg Gynecol Obst 1983; 157: $500-4$
21. Horton JW, White DJ. Lipid peroxidation contributes to cardiac deficits after ischemia and reperfusion the small bowel. Am J Physiol 1993; 264: H1686-H92.

22. Mansberger Jr AR, Cox EF, Flotte CT, Buxton RW. "Washout” acidosis following resection of aortic aneurysms: clinical metabolic study of reactive hyperemia and effect of dextran on excess lactate and pH. Ann Surg 1996; 163: 778-87.

23. Grindlinger GA, Vegas AM, Williams, GH, Mannick JA, Hechtman HB. Independence of renin production and hypertension in abdominal aortic aneurysmectomy. Ann Surg 1981; 141: 472-7.

24. Grant RP, Jenkins LC. Modification by preoperative beta-blockade of the renin response to infrarenal aortic cross-clamping. Can Anaesth Soc J 1983; 30: $480-6$.

25. Kataja JHK, Kaukinen S, Viinamack O, Metsa-Ketela TJA, Vapaatalo H. Hemodynamic and hormonal changes in patients pretreated with captopril for surgery of abdominal aorta. J Cardiothorac Anesth 1989; 3: 425-32.

26. Gelman S. The pathophysiology of aortic cross-clamping and unclamping. Anesthesiology 1995; 82: 1026-60. 